\title{
Changes in vector species composition and current vector biology and behaviour will favour malaria elimination in Santa Isabel Province, Solomon Islands
}

Hugo Bugoro ${ }^{1,2}$, Charlie Iro'ofa', Donna O Mackenzie³, Allen Apairamo', Watson Hevalao', Sarah Corcoran³, Albino Bobogare ${ }^{1}$, Nigel W Beebe ${ }^{4}$, Tanya L Russell ${ }^{5}$, Cheng-Chen Chen ${ }^{2}$ and Robert D Cooper ${ }^{3^{*}}$

\begin{abstract}
Background: In 2009, Santa Isabel Province in the Solomon Islands embarked on a malaria elimination programme. However, very little is known in the Province about the anopheline fauna, which species are vectors, their bionomics and how they may respond to intensified intervention measures. The purpose of this study was to provide baseline data on the malaria vectors and to ascertain the possibility of successfully eliminating malaria using the existing conventional vector control measures, such as indoor residual spraying (IRS) and long-lasting insecticidal nets (LLIN).
\end{abstract}

Methods: Entomological surveys were undertaken during October 2009. To determine species composition and distribution larval surveys were conducted across on the whole island. For malaria transmission studies, adult anophelines were sampled using human landing catches from two villages - one coastal and one inland.

Results: Five Anopheles species were found on Santa Isabel: Anopheles farauti, Anopheles hinesorum, Anopheles lungae, Anopheles solomonis, and Anopheles nataliae. Anopheles hinesorum was the most widespread species. Anopheles farauti was abundant, but found only on the coast. Anopheles punctulatus and Anopheles koliensis were not found. Anopheles farauti was the only species found biting in the coastal village, it was incriminated as a vector in this study; it fed early in the night but equally so indoors and outdoors, and had a low survival rate. Anopheles solomonis was the main species biting humans in the inland village, it was extremely exophagic, with low survival rates, and readily fed on pigs.

Conclusion: The disappearance of the two major vectors, An. punctulatus and An. koliensis, from Santa Isabel and the predominance of An. hinesorum, a non-vector species may facilitate malaria elimination measures. Anopheles farauti was identified as the main coastal vector with An. solomonis as a possible inland vector. The behaviour of An. solomonis is novel as it has not been previously found biting humans in any numbers. Both species appear to be short-lived, a characteristic that will limit their transmission potential. The early night feeding behaviour and a degree of outdoor biting seen in An. farauti and particularly in An. solomonis will require that their response to IRS and LLIN be closely monitored. In coastal villages, where large, favourable breeding sites allow for high numbers of An. farauti may require the addition of larval control to achieve elimination.

\footnotetext{
*Correspondence: Bob.cooper@defence.gov.au

${ }^{3}$ Australian Army Malaria Institute, Gallipoli Barracks, Enoggera, 4052, Australia

Full list of author information is available at the end of the article
} 


\section{Background}

Recently, the international community has prioritized national and regional malaria elimination based on the strategy of shrinking the malaria map from the margins inwards [1]. The Solomon Islands is at the eastern edge of the distribution of malaria in the southwest Pacific, the disease is endemic throughout many parts of the country and up until the early 1990s was the leading public health problem [2]. The Solomon Islands has now entered the malaria pre-elimination stage together with 31 other countries [3]. To initiate this, the country's National Vector Borne Disease Control Programme (NVBDCP) has selected Temotu and Santa Isabel Provinces in which to commence malaria elimination programmes. In the remaining six provinces intensified control will be implemented.

Malaria eradication was attempted in Solomon Islands through a Malaria Eradication Programme (MEP) conducted during 1970 - 1975 [4]. On Santa Isabel, this programme was highly successful and elimination was nearly achieved with entry into the consolidation phase (cessation of DDT - IRS) planned for 1974 [4]. However similar success was not achieved in other parts of the country, most notably on the north coast of Guadalcanal [5]. The MEP was abandoned in 1975 and reduced to control measures and focal DDT indoor residual spraying (IRS) to contain outbreaks. The malaria rate rose during this period peaking in 1992 [2], in 1993 insecticide impregnated bed nets (ITN) were introduced [6] and in early 2000, DDT was replaced by lambdacyhalothrin (ICON) for IRS, also at this time ITNs were being replaced by long-lasting insecticidal nets (LLIN). Through these intervention methods Santa Isabel Province has maintained a continual attack on the vector for the last 40 years with the introduction of ITN and LLIN resulting in a continual fall in transmission rates from $44 \%$ in 1992 to $4.5 \%$ in 2008 [Source: SI NVBDCP data: unpublished]. The current malaria situation on Santa Isabel indicates a further reduction in malaria transmission. Passive case detection at the main hospital in the capital Buala recorded 81 cases over 33 months, January 2007 to September 2009. At least 11 of these cases were reported as being imported from other provinces - Guadalcanal and Malaita. The species composition was Plasmodium falciparum $47 \%$ and Plasmodium vivax 53\%. A mass blood survey conducted on Santa Isabel in October 2009 screened 8552 of the local population. A total of 14 were found positive by microscopy $(\mathrm{n}=1)$ and PCR $(\mathrm{n}=13)$ giving a parasite prevalence rate of $0.16 \%$; of these $92.9 \%$ were due to $P$. vivax and the remainder due to P. falciparum [7].

Several species of anophelines occur in the Solomon Islands, six members of the Anopheles punctulatus group: Anopheles farauti (formerly Anopheles farauti 1), Anopheles irenicus (formerly Anopheles farauti 7), Anopheles hinesorum (formerly Anopheles farauti 2), Anopheles punctulatus, Anopheles koliensis, and Anopheles rennellensis [8,9]; as well as three members of the Anopheles lungae complex: Anopheles lungae, Anopheles solomonis, and Anopheles nataliae [10]. Of these nine species, only An. farauti, An. punctulatus and An. koliensis are considered vectors of malaria [10]. With the latter two species the use of IRS and LLIN over the years appears to have eliminated An. koliensis and $A n$. punctulatus is now uncommon with a patchy distribution [11,12]. The third species, An. farauti, did not respond well to IRS during the MEP and subsequent control programmes due to a change in behaviour to early evening, outdoor biting [12]. This species is now the primary vector in the Solomon Islands, being the most abundant and widespread species [13]. It is primarily a coastal species capable of breeding in brackish water, a trait that has facilitated its spread throughout small island groups [14]. Anopheles farauti is a member of the An. farauti complex within the An. punctulatus group and is morphologically indistinguishable from $A n$. hinesorum and An. irrenicus, the other members of the complex found in the Solomon Islands. As An. hinesorum and An. irenicus are zoophilic, non-vectors species in the Solomon Islands, it is important to accurately identify these species as efforts may be wasted on controlling species of no medical importance.

On Santa Isabel, the last anopheline faunal survey was conducted between 1966 and 1971 [11] with the species composition updated in 1978 [13]. From these records An. farauti s.l., An. punctulatus, An. koliensis, An. lungae, An. solomonis, and An. nataliae were recorded. However, during the past 30 years it is possible that species composition and distribution may have been altered by continual pressure from the vector control programmes as well as biotic factors such as competition and dispersal of zoophilic species. Moreover, as these surveys predate the use of molecular techniques for species identification it is possible that other species may occur on the island. For example by using allozymes, An. hinesorum was identified from two locations around Buala in 1988 [15]. With the molecular based techniques currently available that will reliably identify the members of the An. punctulatus group the presence and distribution of these species on Santa Isabel can now be resolved; however no such techniques are as yet available for identifying the members of the An. lungae complex.

The strategies planned for malaria elimination in Santa Isabel Province are improved and more widely available diagnosis, greater accessibility to more effective treatment drugs, and vector control with LLIN and 
IRS aiming at reducing human vector contact, vector longevity, and vector density. To support the vector control measures information on the speciation, distribution, ecology, behaviour, and biology of the vector is important to ascertain what type of elimination measures are most appropriate and for which areas. The results of these surveys will also provide base line data for future monitoring and evaluation of the elimination programme. As this information is currently lacking for Santa Isabel entomological surveys were conducted in October 2009. This paper reports on the findings of these surveys

\section{Methods}

\section{Study site}

This study was conducted in Santa Isabel Province ( $8^{\circ} 14 ' 21.66^{\prime \prime S}$ latitude and $159^{\circ} 33^{\prime 2} 27.08^{\prime \prime}$ E longitude). The province is made up of the main Santa Isabel Island (200 km long by $25 \mathrm{~km}$ wide) and several closely associated smaller islands. A mountain range, up to $1500 \mathrm{~m}$ above sea level (asl), runs down the center of the island and there is a narrow coastal shelf $(0.1$ $3 \mathrm{~km}$ wide and $<20 \mathrm{~m}$ asl) that runs round the island; the majority of the population live in villages that lie along this coastal shelf. The climate is continuous hot/wet. There is no rainfall data specific to the province but weather stations in surrounding provinces indicate that rain occurs all year round and at a rate of about 2,500$3,000 \mathrm{~mm}$ per annum. The mean temperature for the region is $26-27^{\circ} \mathrm{C}$ on the coast and inland lowland regions. The total population is 26,500 , most of whom live on the eastern end of the island around Buala the provincial capital. There is no road network and all movement is by boat.

\section{Species composition and distribution}

Utilizing marine transport a larval survey was conducted covering most of the island. As the majority of the villages were located on the coast, the survey concentrated on this area; however inland villages were also surveyed. At each location, using local knowledge from the village people, all ground pools were checked around the villages. Using standard $250 \mathrm{ml}$ dippers, larval samples were taken from all sites positive for anopheline larvae. A description of the site was made and its location georeferenced on 1:50,000 scale maps. The anopheline larvae collected from each site were preserved in $70 \%$ ethanol in appropriately labeled vials.

\section{Selection of indicator villages for adult collections}

Two indicator villages - Kolosori and Popoheo - were selected for studying the biology and behaviour of the adult anopheline fauna. Kolosori ( $8^{\circ} 07^{\prime} 13.21^{\prime \prime} \mathrm{S}, 159^{\circ}$ $\left.31^{\prime} 49.96^{\prime \prime} \mathrm{E}\right)$ is located on the coastal plain about $3.0 \mathrm{~km}$ inland and $20 \mathrm{~m}$ asl and Popoheo ( $8^{\circ} 05^{\prime} 34.18^{\prime \prime} \mathrm{S}, 159^{\circ}$ $\left.31^{\prime} 24.10^{\prime \prime} \mathrm{E}\right)$ on the same plain but directly on the coast $(<5 \mathrm{~m}$ asl) and surrounded by brackish water swamps. Both villages were chosen in the vicinity of Buala for reliable access. Three houses in each of these villages were randomly selected for the indoor human landing catches. In Kolosori a host preference study was carried out comparing the attractiveness of paired human and pig baits.

\section{Human landing catches (HLC)}

Local villagers from Buala were hired and trained to perform the human landing catches. For each indicator village, 12 collectors were hired, with six working from $6 \mathrm{pm}$ to midnight and the other six working from midnight to $6 \mathrm{am}$. Collections were made for 10 nights in each indicator village.

Three collectors worked indoors and three outdoors. Each collector collected for $40 \mathrm{~min}$ each hour; during this period the collectors, using a torch and aspirator, caught all anophelines coming to feed on their exposed legs and feet. Specimens collected were held in separate cups labelled for each hour, either outdoors or indoors. The collectors were alternated with regards to indoor/ outdoor and collection time either the first or second parts of the night. The cups were covered with damp cotton wool and held until the following morning when the mosquitoes were killed using chloroform, morphologically identified [10] and the hourly collection rates recorded. All adult mosquitoes collected were preserved, desiccated on silica gel, in microfuge tubes each labelled with the village, date, time of feeding, method of collection and whether collected indoor or outdoor.

\section{Longevity of vector populations}

Parity was determined based on the condition of the tracheolar skeins of the ovaries [16] this was done on all anophelines collected each hour from the night landing collections. From this the proportion parous (P) was used to determined the survival through one day $(p)$ as $x \sqrt{\mathrm{P}}$ where $x$ is the length of the gonotrophic cycle. The proportion of the vector population living long enough to transmit malaria parasites was determined by $p^{n}$ where $\mathrm{n}$ was 9 days for $P$. vivax and 12 days for $P$. falciparum [17].

\section{Human host behavior}

A census of the people outdoors each hour from $6 \mathrm{pm}$ 6 am was conducted in each of the indicator villages on each night that the human landing catches were performed. Based on the total number people in the village, the number of people indoors each hour was then determined and related to the biting times of the anophelines. 


\section{Host seeking in relation to host indoor/outdoor movements}

The use of indoor and outdoor collectors creates an artificial situation where for example mosquitoes collected outdoors, late in the night when no village people are outdoors, are counted as outdoor biting. It is more realistic when estimating the degree of indoor (or outdoor) biting to account for the spatial interaction between the vector and the host, resulting from the movement of vectors and hosts in and out of houses. This is particularly so where the vector control tools (IRS and LLIN) being implemented only target indoor biting mosquitoes. The degree of indoor or outdoor biting will be a factor of where the people are at the time of vector host seeking. Thus the proportion of indoor biting mosquitoes $\left(\pi_{\mathrm{i}}\right)$ was calculated by multiplying the number of Anopheles biting indoors with the number of people indoors for each hour of the night and similarly the outdoor biting component $\left(\pi_{\mathrm{o}}\right)$ was multiplied by the number of people outdoors for each hour of the night. The mathematical formulae for estimating $\pi_{i}$ have been detailed previously [18].

\section{Molecular identification of mosquitoes}

All specimens collected were initially identified using morphological keys [10]. As many of the Anopheles species in the Solomon Islands belong to isomorphic species complexes the morphological identification of the specimens collected was verified using polymerase chain reaction - restriction fragment length polymorphisms (PCR-RFLP) of the ITS2 region of the ribosomal DNA [19]. Up to 10 individual larvae from each larval collection site, and all of the adults from the human landing catches and the animal baited traps were processed. DNA extraction, amplification, restriction digest, fragment separation, and visualization are as previously described [20]. With any anomalies or unknown RFLP then the ITS2 was sequenced for that specimen and compare to the existing sequences in the GenBank [20].

\section{Vector incrimination}

The head and the thorax of all adult mosquito specimens collected biting humans and from bait net traps were processed using specific monoclonal antibodies and an enzyme-linked immunosorbent assay (ELISA). The methods used were those supplied with the monoclonal reagents (Dr Robert Wirtz, Centers for Disease Control and Prevention, MS F42, Atlanta, GA 303413717, USA). Specimens were considered positive if the absorbance value was twice that of the average negative control value and all positives were rerun for confirmation.

\section{Animal host preference}

Two animal baited traps were set up, one containing a human, the other two small pigs. To protect the human bait the person slept inside a normal untreated bed net covered by the animal bait-net. With both the human and pig traps, the skirt of the nets were raised $10 \mathrm{~cm}$ off the ground at $6 \mathrm{pm}$ each evening to allow entry of blood seeking mosquitoes during the night and lowered at 6 am each morning. The traps were inspected at 7 am each morning and all trapped mosquitoes were collected, counted and scored for unfed or blood fed.

\section{Ethics}

Ethical approval for the study was obtained from the University of Queensland Medical Research Ethics Committee (2010000412).

\section{Results}

\section{Anopheles species identification}

All adults were initially identified using morphological keys, with specimens of $A n$. farauti s.l. and those of the An. lungae complex being identified. Following this, the application of PCR-RFLP techniques revealed the presence of $A n$. farauti and An. hinesorum. Similar PCR techniques when applied to the specimens morphologically identified as members of the An. lungae complex demonstrated the presence of three species which, when sequenced and compared to material in GenBank, were found to be $A n$. lungae and $A n$. solomonis. For the third species there was no match but this species is most likely $A n$. nataliae, the third member of this complex, as morphological and sequence similarities placed it in the An. lungae complex. Therefore the digest enzyme MspI used in this PCR method was able to separate not only the members of the An. farauti complex in the Solomon Islands but also the members of the An. lungae complex (Figure 1). From the larval collections 1070 specimens were processed using PCR with six species identified: $A n$. farauti, An. hinesorum, An. lungae, $A n$. solomonis, An. nataliae, and Bironella hollandi. The genus Bironella belongs to the subfamily Anophelinae, the larvae are macroscopically similar to Anopheles; this species was identified here by comparing ITS2 sequences in the Gen-Bank.

\section{Anopheles species distribution and larval ecology}

Anopheline larvae were collected from 146 sites throughout the island (Figure 2). Anopheles hinesorum was the most abundant and widespread of all species being found in $82.2 \%(120 / 146)$ of positive sites both inland and along the coast. Anopheles farauti was less common with collections from $19.9 \%$ of sites positive but with a distribution restricted to the coast. Members of the An. lungae complex were widespread throughout 


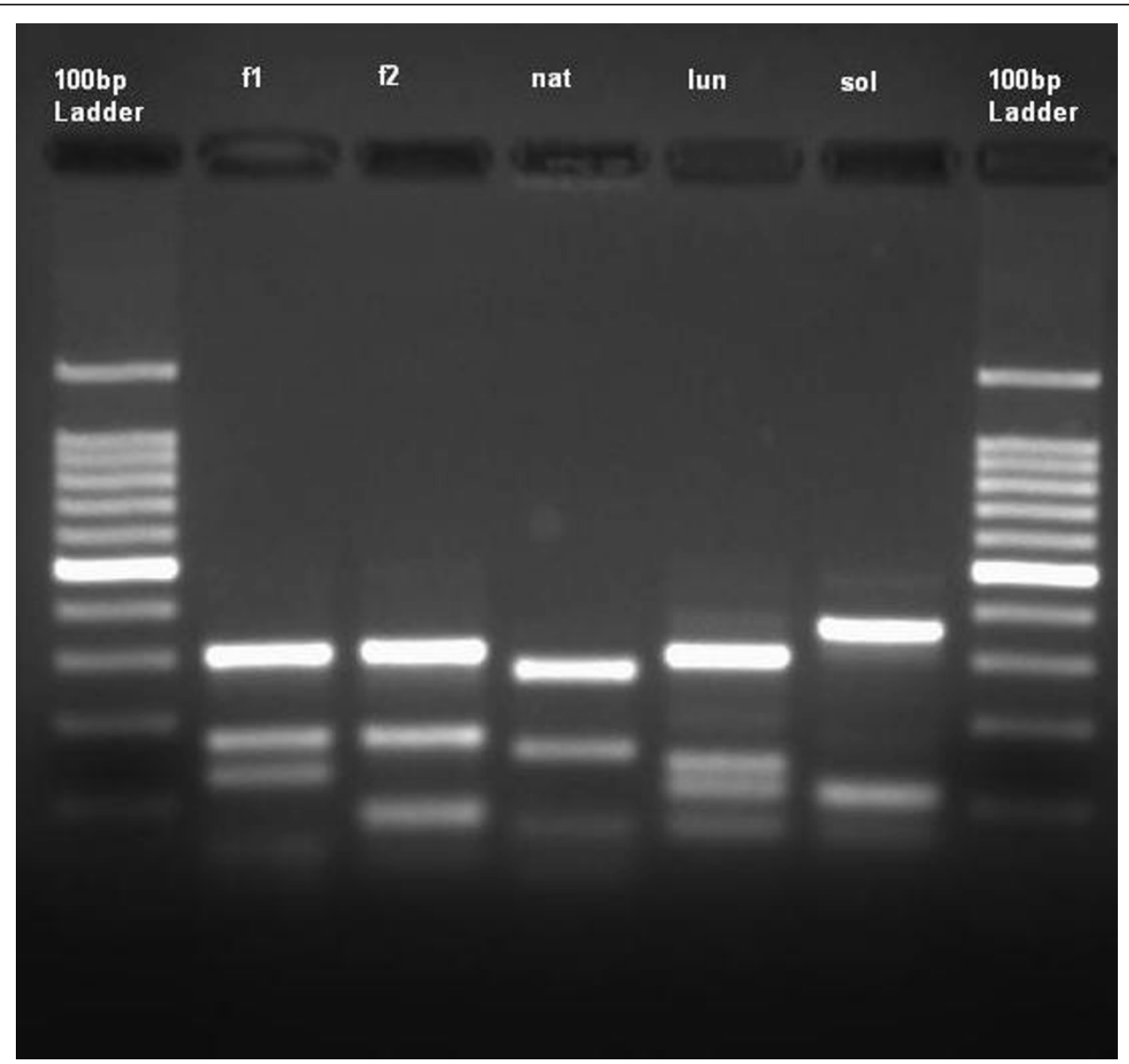

Figure 1 Internal transcribed spacer 2 amplification products from: Anopheles farauti (f1), Anopheles hinesorum (f2), Anopheles nataliae (nat), Anopheles lungae (lun), and Anopheles solomonis (sol), digested with Msp I and run on a 3\% agarose gel with a 100 base pair ladder.

the island being found both coastal and inland but like An. farauti were less common than An. hinesorum. Breeding sites were categorized broadly into six main types (Table 1). Anopheles hinesorum was collected from all types of sites except tidal swamps, but was most commonly found in transient (Figure 3 ) and semipermanent ground pools. Anopheles farauti was found in brackish water but also in fresh water habitats, all coastal. Members of the An. lungae complex preferred shaded, heavily vegetated sites mostly associated with drains, creeks and water courses.

\section{Species biting humans and their biting density in two indicator villages}

In Popoheo, the only species collected during HLC was An. farauti. Over the 10 nights of collection, 775 An. farauti were collected, with a landing rate of 12.9 / person/night (Table 2).

At the inland village of Kolosori, 304 anophelines were collected in ten nights of human landing catches. These were identified by PCR as $285 \mathrm{An}$. solomonis, $10 \mathrm{An}$. farauti, and nine An. hinesorum. Thus, the most common anopheline biting humans in this inland village was $A n$. solomonis with a landing rate of $4.75 /$ person/night (Table 3).

\section{Biting behaviour}

In Popoheo, the majority of An. farauti host seeking occurred early in the evening (Table 2) with $52.3 \%$ of the mosquito population active between $6-8 \mathrm{pm}$. Biting virtually ceased after mid-night except for a pre dawn peak between 5 - 6 am. Equal numbers of An. farauti fed indoors and outdoors even early in the evening between $6-9 \mathrm{pm}$ when $68.7-35.4 \%$ of the village population was outdoors. Over the ten nights the average outdoor to indoor biting ratio was 1:0.93.

In Kolosori, the majority of An. solomonis host-seeking took place early in the evening (Table 3 ) with $51.2 \%$ of the mosquitoes collected in the first hour of the night (6 $-7 \mathrm{pm}$ ) and $74.2 \%$ of biting occurring within the first three hours of the night. This peak biting period of $A n$. solomonis coincided with the highest number of people outdoors (Table 3 ). This early night feeding and a predominantly outdoor human population at this time of 


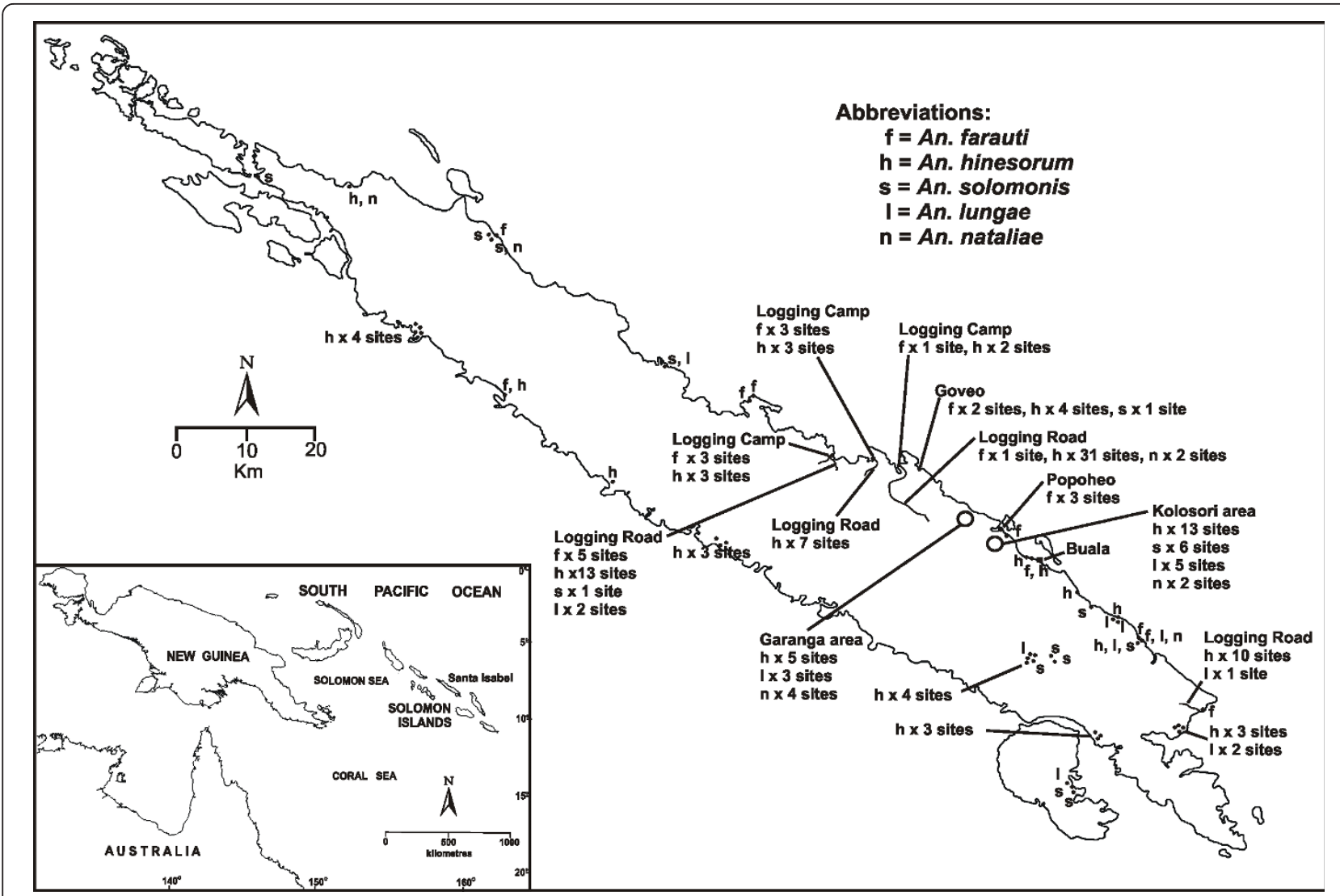

Figure 2 Speciation and distribution of anopheline fauna on Santa Isabel based on larval surveys conducted in October 2009. Insert is the map of the Southwest Pacific.

the evening (Table 3) allows for a high degree of outdoor biting and the overall outdoor to indoor biting ratio for the ten nights was 1:0.2.

\section{Interaction between human hosts and vectors}

In Popoheo, the biting times of An. farauti were correlated with the movement of people indoors during the night to provide a more realistic assessment of the amount of indoor biting $\left(\pi_{\mathrm{i}}\right)$. This indicated that on average, each night, $54.6 \%$ of biting occurred indoors. For An. solomonis in Kolosori, adjusting for the movement of people outdoors to indoor during the night indicated that only $6.9 \%$ of biting occurred indoors.

Table 1 Aquatic larval habitats utilized by the six species found on Santa Isabel.

\begin{tabular}{|c|c|c|c|c|c|c|}
\hline \multirow[t]{2}{*}{ Type of site } & \multicolumn{6}{|c|}{ Species and number of sites occupied (\%) } \\
\hline & An. farauti & An. hinesorum & An. lungae & An. solomonis & An. nataliae & B. hollandi \\
\hline Swamps tidal & $6(20.7 \%)$ & 0 & 0 & 0 & 0 & 0 \\
\hline Swamps fresh & $2(6.9 \%)$ & $4(3.3 \%)$ & $3(13.6 \%)$ & $3(15.8 \%)$ & $1(12.5 \%)$ & 0 \\
\hline Riparian & 0 & $6(5.0 \%)$ & $8(36.4 \%)$ & $7(36.8 \%)$ & $3(37.5 \%)$ & $5(83.3 \%)$ \\
\hline Drains & $6(20.7 \%)$ & $27(22.5 \%)$ & $7(31.8 \%)$ & $9(47.4 \%)$ & $1(12.5 \%)$ & 0 \\
\hline Ground pools, semi-permanent & $11(37.9 \%)$ & $40(33.3 \%)$ & $3(13.6 \%)$ & 0 & $3(37.5 \%)$ & $1(16.7 \%)$ \\
\hline Ground pools, transient & $4(13.8 \%)$ & $43(35.8 \%)$ & $1(4.5 \%)$ & 0 & 0 & 0 \\
\hline Total & 29 & 120 & 22 & 19 & 8 & 6 \\
\hline
\end{tabular}

Where riparian sites included pools in creek lines and the margins along creeks usually heavily vegetated and shaded. Drains were all earthen, slow flowing, usually heavily vegetated and shaded. Semi-permanent ground pools refers to small to medium pools of water well established with vegetation in and around the site, well developed aquatic flora and fauna, usually shaded. Examples: borrow pits, large vehicle tracks, blocked creeks and water courses, natural rain filled depressions. Transient ground pools were those maintained only by regular rainfall they were unestablished with no vegetation or fauna usually exposed, unshaded and with a clay substrate. Examples: vehicle tracks, small natural depressions, pig wallows, foot prints, ruts in roads and foot tracks (Figure 3). 


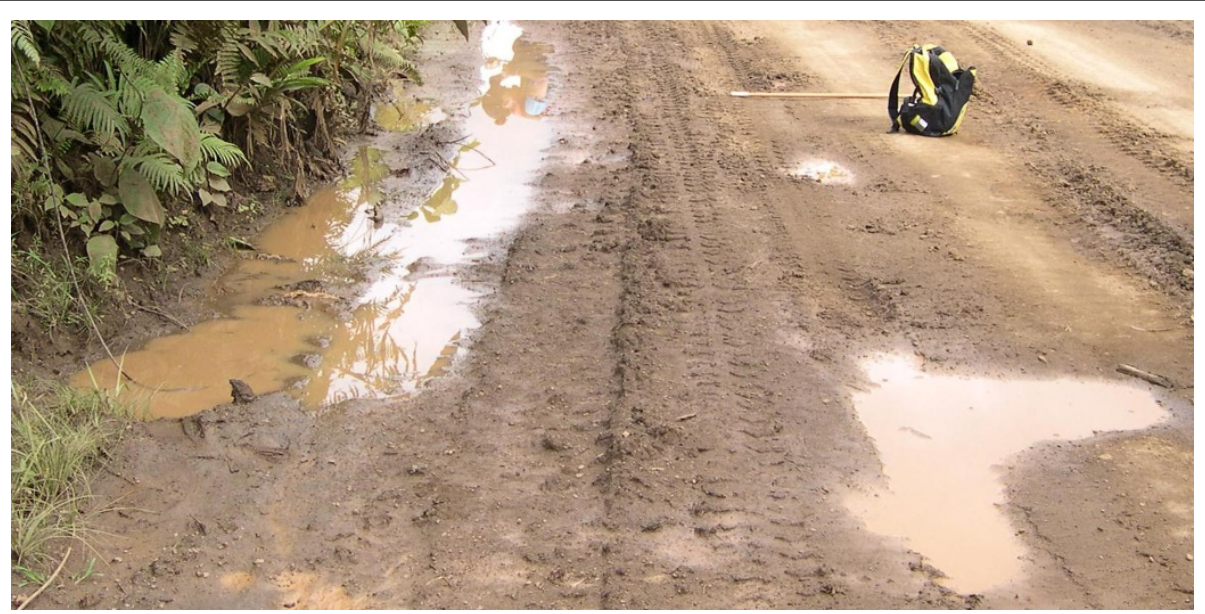

Figure 3 Typical transient ground pools, in this case wheel ruts - small, turbid, with clay substrate, and devoid of any flora or fauna In the past these sites were used exclusively by Anopheles punctulatus, on Santa Isabel they are now being used exclusively by Anopheles hinesorum.

\section{Longevity of the mosquito populations}

Age grading, by estimating the proportion of the mosquito population that had previously laid at least one batch of eggs, was carried out at Popoheo for An. farauti. The overall proportion parous for this species was 0.411 ( $\mathrm{n}=632$ dissected) as the duration of the gonotrophic cycle is 2.5 days for An. farauti in the Solomon Islands [21] the daily survival rate was 0.70 . The extrinsic phase (time for the malaria parasite to develop in the mosquito) for $P$. vivax and $P$. falciparum is 9 and 12 days respectively at $26-27^{\circ} \mathrm{C}$ [17], the mean coastal temperature for most parts of the Solomon Islands [22]. Thus with this population of An. farauti only $4.0 \%$ and

Table 2 Human landing collections of An. farauti and host movements in Popoheo village.

\begin{tabular}{ccccc}
\hline $\begin{array}{c}\text { Time } \\
\text { pm-am }\end{array}$ & $\begin{array}{c}\text { No. collected } \\
\text { outdoors }\end{array}$ & $\begin{array}{c}\text { No. collected } \\
\text { indoors }\end{array}$ & $\begin{array}{c}\text { \% of total } \\
\text { catch }\end{array}$ & $\begin{array}{c}\text { \% of villagers } \\
\text { outdoors }\end{array}$ \\
\hline $6-7$ & 100 & 101 & 25.9 & 68.7 \\
$7-8$ & 104 & 100 & 26.3 & 51.1 \\
$8-9$ & 54 & 43 & 12.5 & 35.4 \\
$9-10$ & 39 & 38 & 9.9 & 24.0 \\
$10-11$ & 27 & 25 & 6.7 & 13.4 \\
$11-12$ & 21 & 22 & 5.5 & 7.6 \\
$12-1$ & 2 & 4 & 0.8 & 10.0 \\
$1-2$ & 3 & 5 & 1.0 & 10.1 \\
$2-3$ & 9 & 2 & 1.4 & 8.1 \\
$3-4$ & 5 & 3 & 1.0 & 11.0 \\
$4-5$ & 7 & 4 & 1.4 & 13.8 \\
$5-6$ & 32 & 25 & 7.4 & 26.4 \\
\hline Totals & 403 & 372 & 100 & \\
\hline
\end{tabular}

Collections were made each hour ( $6 \mathrm{pm}-6 \mathrm{am})$ over 10 nights by three collectors indoors and three collectors outdoors and the percentage of the village population outdoors for each hour (based on a mean of 10 nights and a total village population of 70 ).
$1.4 \%$ of mosquitoes would live long enough to transmit $P$. vivax and $P$. falciparum respectively.

In Kolosori, the overall proportion parous for An. solomonis was 0.333 ( $\mathrm{n}=221$ dissected) assuming a similar duration for the gonotrophic cycle this equates to a daily survival rate of 0.64 . Thus with this population of An. solomonis only $1.8 \%$ and $0.47 \%$ of mosquitoes would live long enough to transmit $P$. vivax and $P$. falciparum respectively..

\section{Host preference}

In Kolosori, a direct comparison was made between the number of Anopheles species coming to bite humans

Table 3 Human landing collections of An. solomonis and host movements in Kolosori village.

\begin{tabular}{ccccc}
\hline $\begin{array}{c}\text { Time } \\
\text { pm-am }\end{array}$ & $\begin{array}{c}\text { No. collected } \\
\text { outdoors }\end{array}$ & $\begin{array}{c}\text { No. collected } \\
\text { indoors }\end{array}$ & $\begin{array}{c}\% \text { of total } \\
\text { catch }\end{array}$ & $\begin{array}{c}\% \text { of villagers } \\
\text { outdoors }\end{array}$ \\
\hline $6-7$ & 130 & 17 & 51.6 & 100 \\
$7-8$ & 26 & 15 & 14.4 & 85.7 \\
$8-9$ & 21 & 4 & 8.8 & 66.0 \\
$9-10$ & 13 & 2 & 5.3 & 36.5 \\
$10-11$ & 10 & 2 & 4.2 & 28.2 \\
$11-12$ & 9 & 3 & 4.2 & 22.7 \\
$12-1$ & 5 & 0 & 1.8 & 19.5 \\
$1-2$ & 7 & 2 & 3.2 & 13.2 \\
$2-3$ & 1 & 1 & 0.7 & 14.8 \\
$3-4$ & 2 & 2 & 1.4 & 12.7 \\
$4-5$ & 1 & 0 & 0.4 & 11.8 \\
$5-6$ & 12 & 0 & 4.2 & 22.5 \\
\hline Totals & 237 & 48 & 100 & \\
\hline
\end{tabular}

Collections were made each hour ( 6 pm- 6 am) over 10 nights by three collectors indoors and three collectors outdoors and the percentage of the village population outdoors for each hour (based on a mean of 10 nights and a total village population of 60 ). 
and pigs. Over 10 nights, 44 An. solomonis and two An. hinesorum were collected off pigs but none of either species were collected off the paired human bait. This indicated that while this species will feed on humans, as was shown in the HLC results, it also has a preference for non-human hosts.

\section{Detection of circumsporozoite antigen and EIR}

In Popoheo, 775 specimens of $A n$. farauti were assayed for circumsporozoite antigen with one positive for $P$. vivax (210 variant). The specimen was collected indoors between 9-10 pm. The sporozoite rate for An. farauti in Popoheo village was 0.00129 , with a biting rate of 12.9 bites/person/night this represents an EIR of 6.07 infective bites/person/year (Table 4).

In Kolosori, 304 specimens were tested for circumsporozoite antigens. Of the 304 specimens, 285 of them were An. solomonis, $10 \mathrm{An}$. farauti, 9 An. hinesorum and all were negative.

\section{Malaria prevalence in the two indicator villages}

Of the 14 positive cases detected during the mass blood survey of November 2009, two P. vivax cases occurred in Popoheo $(0.91 \%$ [2/219]) and one P. vivax case in an adjacent coastal village Hovikoila $1.5 \mathrm{~km}$ to the north. No malaria cases were found in Kolosori village. In May 2010 four cases of $P$. vivax were detected by PCD in Popoheo village [7]. These findings indicate a persistent but low rate of malaria transmission is occurring in the study area.

\section{Discussion}

A major finding of this work is the absence of $A n$. punctulatus and An. koliensis from Santa Isabel. These two primary vectors of malaria were recorded on the island in 1970, at the time An. punctulatus was uncommon, but An. koliensis was common and widespread [8]. Their disappearance is most likely due to years of IRS, first with the MEP and then the on-going control programme. This occurred in New Guinea and in other parts of the Solomon Islands when IRS was introduced, though with the cessation of the eradication programmes or a reduction in IRS coverage they rebounded $[11,12,23,24]$.

A further factor which may have helped with their elimination is competition from $A n$. hinesorum; which was found to be dominant anopheline species on Santa Isabel. Anopheles hinesorum occupied breeding sites commonly used by An. koliensis, particularly drains and semi-permanent ground pools. It was also commonly found in transient ground pools (Figure 3). These sites are normally used exclusively by $A n$. punctulatus [14] to the point where when An. farauti and An. koliensis larvae were seeded into these types of sites they failed to develop [25]. Anopheles hinesorum populations in the Solomon Islands are zoophilic and are not involved in malaria transmission [26,27]. The disappearance of $A n$. punctulatus and An. koliensis and their replacement by a zoophilic, non-vector species is likely responsible for some of the decline in transmission rates, particularly in inland villages.

Anopheles farauti, the third major malaria vector in the Solomon Islands, was common on Santa Isabel, it was found predominantly on the coast where the majority of the human population is located. The larvae of An. farauti will develop in brackish water and as found here in Popoheo and recently in coastal villages in Temotu Province large brackish coastal swamps are the most productive sites for this species; these site can be responsible for high human biting densities [21].

Table 4 The entomological estimation of malaria transmission intensity attributable to Anopheles farauti on Popoheo village and Anopheles solomonis on Kolosori village, Santa Isabel province, Solomon Islands during October of 2009.

\begin{tabular}{lll}
\hline Entomological parameters of mosquito population & Popoheo Anopheles farauti & Kolosori Anopheles solomonis \\
\hline Sporozoite prevalence $(\mathrm{S} ; \%)$ & $0.00129(n=775)$ & $0.0000(n=287)$ \\
\hline Biting rate $(\mathrm{B} ; \mathrm{b} / \mathrm{p} / \mathrm{n})$ & 12.4 & 1.6 \\
$\quad$ Indoor & 13.4 & 8.0 \\
$\quad$ Outdoor & 12.9 & 5.1 \\
$\quad$ Overall & 6.07 & $<0.001$ \\
\hline Entomological inoculation rate ib/p/y & $0.46 \pm 0.04(n=775)$ & $0.21 \pm 0.06(n=287)$ \\
\hline Endophagy Proportion indoors $\pm \mathrm{se}$ & $0.03 \pm 0.01(n=775)$ & $0.02 \pm 0.01(n=287)$ \\
\hline Nocturnal biting ${ }^{2}$ Proportion $10 \mathrm{pm}-5 \mathrm{am} \pm \mathrm{se}$ & 0.546 & 0.069 \\
\hline Proportion indoor biting ${ }^{3}\left(\pi_{\mathrm{i}}\right)$ & &
\end{tabular}

Where $S=$ no. of sporozoite positive mosquitoes/no. of mosquitoes tested, $B=$ no. of mosquitoes collected/no. of nights/no. of collectors, EIR $=S \times B$ overall $\times 365$. Endophagy was the proportion of mosquitoes caught indoors (calculated as $I_{6} \mathrm{pm} \rightarrow_{5}$ am $/\left(I_{6} \mathrm{pm} \rightarrow 5\right.$ am $+O_{6} \mathrm{pm} \rightarrow 5$ am, where $I$ and $O=$ the total number of mosquitoes caught indoors and outdoor respectively between $6 \mathrm{pm}$ and $5 \mathrm{am}$ ); nocturnal biting was the proportion of mosquitoes caught during hours (10 pm-5 am) when most people are asleep (calculated as $I_{9} \mathrm{pm} \rightarrow_{4}$ am $+O_{9} \mathrm{pm} \rightarrow_{4}$ am $) /\left(I_{6} \mathrm{pm} \rightarrow_{5}\right.$ am $+O_{6}$ pm $\rightarrow_{5}$ am where $I$ and $O=$ the total number of mosquitoes caught indoors and outdoor respectively at the time indicated); and $\pi_{i}$ the proportion of the vector population biting indoors adjusted for the location of the host either outdoors or indoors [12] 
In this study, $A n$. farauti was incriminated as a vector for vivax malaria in Popoheo, and is most likely the main vector on Santa Isabel. There have been problems in the past with the control of this species. Of concern is its shift to early night outdoor feeding thought to be due to an excito-repellent response to the IRS. This change in biting behaviour allowed it to avoid the insecticide and maintain transmission outdoors limiting the effectiveness of past eradication and control programmes [5,12,28]. In Popoheo An. farauti was found to be an early night feeder with $52.3 \%$ of host seeking occurring between $6-8 \mathrm{pm}$, however it was still quite endophagic and readily enter houses to feed even during the early hours of the night when considerable numbers of villagers were outdoors. This is anomalous with $A n$. farauti populations in other parts of the Solomon Islands where similar intervention measures resulted in outdoor/indoor feeding ratios of 1:0.25 [12,15]. Whether on Santa Isabel the withdrawal of IRS, with only occasional focal spraying, has removed the insecticide pressure allowing for a return to indoor biting is not known. Adjusting outdoor and indoor biting for the movement of people from outdoors to indoors during the night, it is estimated that $54.6 \%$ of the biting of $A n$. farauti occurs indoors each night and that this proportion of the vector population could be controlled if good coverage of IRS and LLIN was achieved in the implementation of the elimination programme.

In the inland village of Kolosori, An. solomonis was recorded as the dominant human biting anopheline. This is the first time this species has been found biting humans in appreciable numbers, prior to this there was very little evidence for considering this species as a possible malaria vector [10]. Anopheles solomonis had a pronounced early night feeding pattern and it was extremely exophagic. This type of behavior would make this species difficult to control with IRS or LLIN. The results of the host preference study indicated that An. solomonis would readily feed on pigs (4.6/night) with no specimens collected off the paired human bait, though at the same time the night biting catches recorded an overall biting rate of $4.75 \mathrm{~b} / \mathrm{p} / \mathrm{n}$. A mass blood survey conducted in Kolosori village at the same time as the entomological survey found no positive malaria cases and all (285) human biting An. solomonis assayed for circumsporozoite antigen were negative.

Kolosori was the only place in the Solomon Islands to date where $A n$. hinesorum has been found biting humans; this was in very low numbers (2.96\% [9/304]), particularly in light of the number of larval sites positive for this species (13 sites) in the immediate vicinity of Kolosori village. This species is inconsequential with regards to malaria transmission. These finding support previous work on this species in the Solomon Islands where it has been identified as a zoophilic species [26,27].

The malaria vector $A n$. farauti was also found biting humans in inland Kolosori but in small numbers $(3.29 \%$ $[10 / 304])$. The flight range for this species is up to 3 kilometers [29], and in the absence of An. farauti larvae in the Kolosori area it is most likely that these few specimens have come in off the coast. From a malaria transmission point of view, these low numbers are unlikely to contribute to malaria transmission, though the possible continued presence of this species in these inland villages should be monitored. The proportion parous was low for both $A n$. farauti and An. solomonis, being 0.41 , and 0.33 respectively. These values are indicative of short-lived populations with only a very few specimens living long enough to transmit the parasite. For An. farauti in other parts of its range in the Solomon Islands and Papua New Guinea considerably higher survival rates, ranging from 0.55 to 0.80 , have been recorded $[4,30]$.

Unlike the provinces of Guadalcanal and Malaita, where malaria is more intense, the disease does not seem to be well entrenched on Santa Isabel. Since the MEP of the early 1970s, continued use of focal IRS, and the introduction of insecticide treated nets in 1993, has seen a decline in the malaria cases with an overall parasite rate of $0.26 \%$ being recorded in 2009 . The mass blood survey conducted in October 2009 estimated a similarly low overall parasite rate of $0.16 \%$ [7]. The reason for the decline in malaria rates is most likely to be due to the elimination of An. koliensis and An. punctulatus from Santa Isabel leaving An. farauti as the only recognized vector. This species can be an efficient vector of malaria and in villages on Guadalcanal it has been responsible for maintaining parasite rates of 30-46\% [30]. However on Santa Isabel, despite reasonable biting densities at Popoheo, the sporozoite rate was 0.00129 and only two human cases were found in the village during the mass blood survey of 2009 [7]. It is possible that there is sufficient indoor host-seeking to result in some degree of $A n$. farauti exposure to insecticide treated nets or IRS which may be responsible for the low survival rate of this species on Santa Isabel and thus its poor vectoring ability. It was found on Guadalcanal, that the introduction of insecticide-treated nets resulted in a parous rate in $A n$. farauti of 0.39 as compared to 0.55 in a no-net site and 0.57 in a DDT IRS site [30].

With $A n$. farauti restricted to the coast and the disappearance of $A n$. koliensis and An. punctulatus, the inland villages ( $>3$ kilometers from the coast) of Santa Isabel should be malaria free unless $A n$. solomonis plays some role in transmission. Even if this species was capable of transmitting the parasites, its low biting 
densities, a degree of zoophilia, and very low survival rates would make it a particularly inefficient vector.

In the Solomon Islands, factors that have been shown to play a lead role in the decline of malaria rates are IRS, LLIN, and education [2]. On Santa Isabel all three of these factors are currently implemented. Additionally the communities on Santa Isabel have a national reputation for a high level of active participation and support for self-betterment. Such community attitudes promote high levels of acceptance for activities like malaria awareness and education plus support and good cooperation for the implementation of IRS and LLIN intervention measures.

On Santa Isabel, malaria elimination is being sought through LLIN distribution to all households in all villages throughout the province in addition to complete and thorough IRS coverage in all houses in all villages along the coast targeting the distribution of the main vector An. farauti. This is a realistic approach as IRS is very labour intensive and costly and just focusing on the main vector allows for a concentration of resources where most needed. Additional to vector control there will be better access to diagnosis and treatment with the recent introduction of a new treatment drug Coartem ${ }^{\circledR}$ (artemether + lumefantrine) to replace chloroquine which has become increasingly ineffectual due to $P$. falciparum and $P$. vivax resistance. The effect of these measures on the already declining parasite rate should see the achievement of malaria elimination from Santa Isabel though the impact of the IRS and LLIN on $A n$. farauti will have to be monitored as will the possible role An. solomonis might play in transmission in inland villages.

\section{Conclusion}

With regards to the vectors, there are a number of factors that will favour the success of renewed efforts in malaria elimination on Santa Isabel. The disappearance of the competent malaria vectors An. punctulatus and An. koliensis and interspecific competition against all species from $A n$. hinesorum, a zoophilic, non-vector species. The restriction of the only recognized vector, $A n$. farauti, to the coast will allow for elimination strategies to be focused and intensified in the coastal areas. The indoor biting activity (despite its early night feeding behaviour) of $A n$. farauti will enhance the effectiveness of IRS while the low survival rate of this species will be a mitigating factor against high rates of transmission. The finding of $A n$. solomonis as a possible inland vector should be monitored, but its low survival rates and zoophilic tendencies may limit its ability to be an effective vector. The impact of IRS and/or LLIN on both An. farauti and An. solomonis will require close monitoring as both species show varying degrees of early night outdoor biting, particularly in An. solomonis, also $A n$. farauti has been found, in other part of the Solomon Islands, to shift to early outdoor biting under insecticidal pressure.

\section{Acknowledgements}

We thank the staff at the National Vector Borne Disease Control Programme especially Landry Losi, Simon Thompson Togapura, Richard Meimana, Andrew Baron and Luke Marston for technical assistance when conducting entomological surveillance. This work was funded by an AusAID grant for the Pacific Malaria Initiative. The authors are grateful to the communities in Santa Isabel Province for cooperating in the surveys. The opinions expressed herein are those of the author's and do not necessarily reflect those of the Australian Defence Organisation, Joint Health Command or any extant policy.

\section{Author details}

${ }^{1}$ National Vector Borne Disease Control Programme, Ministry of Health, Honiara, Solomon Islands. ${ }^{2}$ Institute of Tropical Medicine, National Yang-Ming University, No. 155, Sec.2, Li-Nong Street, Taipei 112, Taiwan. ${ }^{3}$ Australian Army Malaria Institute, Gallipoli Barracks, Enoggera, 4052, Australia. ${ }^{4}$ School of Biological Sciences, University of Queensland, Goddard Building, St.Lucia, Qld 4068, Australia. ${ }^{5}$ The University of Queensland, School of Population Health, Australian Centre for Tropical and International Health, Pacific Malaria Initiative Support Centre, Herston, 4006, Australia.

\section{Authors' contributions}

Conceived and designed the experiments: $\mathrm{HB}, \mathrm{RDC}, \mathrm{AB}$. Performed the experiments: HB, RDC, TLR, SC, DOM, Cl, AA, WH. Performed the molecular analysis: NB, DOM. Analyzed the data and wrote the manuscript: $H B, R D C$, TLR. Reviewed the manuscript: AB, DOM, TLR, CCC. All authors have read and approved the final manuscript.

\section{Competing interests}

The authors declare that they have no competing interests.

Received: 12 May 2011 Accepted: 30 September 2011 Published: 30 September 2011

\section{References}

1. Feachem $R$, Sabot $O$ : A new global malaria eradication strategy. Lancet 2008, 371:1633-1635.

2. Over M, Bakotee B, Velayudhan R, Wilikai P, Graves PM: Impregnated nets or DDT residual spraying? Field effectiveness of malaria prevention techniques in Solomon Islands 1993-1999. Am J Trop Med Hyg 2004, 71:214-223.

3. Feachem R, Jimee Hwang A, Cotter C, Wielgosz B, Greenwood B, Sabot O, Rodriguez M, Abeyasinghe R, Snow R: Shrinking the malaria map: progress and prospects. Lancet 2010, 376:1566-1578.

4. Avery J: A review of the malaria eradication programme in the British Solomon Islands 1970-1972. Papua New Guinea Med J 1974, 17:50-60.

5. Paik $\mathrm{Y}-\mathrm{H}$, Avery JG: Problem areas in the malaria eradication programme in the British Solomon Islands. Papua New Guinea Med J 1973, 17:61-67.

6. Kere NK, Arabola A, Bakote'e B, Qalo O, Burkot TR, Webber RH, Southgate BA: Permethrin-impregnated bednets are more effective than DDT house-spraying to control malaria in Solomon Islands. Med Vet Entomol 1996, 10:145-148.

7. Johnson ML: Malaria Baseline Survey, Isabel Province, Solomon Islands, 1 October - 30 October 2009. Unpublished PacMISC Trip Report University of Queensland, Brisbane; 2010, 6.

8. Beebe NW, Bakotee H, Ellis JT, Cooper RD: Differential ecology of Anopheles punctulatus and three members of the Anopheles farauti complex of mosquitoes on Guadalcanal, Solomon Islands, identified by PCR-RFLP analysis. Med Vet Entomol 2000, 41:308-312.

9. Schmidt ER, Foley DH, Bugoro H, Bryan JH: A morphological study of the Anopheles punctulatus group (Diptera: Culicidae) in the Solomon Islands, with a description of Anopheles (Cellia) irenicus Schmidt, sp.n. Bull of Entomol Res 2003, 93:515-526. 
10. Belkin JN: The mosquitoes of the South Pacific (Diptera, Culicidae). Berkeley and Los Angeles: University of California Press; 1962.

11. Taylor B: Observations on malaria vectors of the Anopheles punctulatus complex in the British Solomon Islands Protectorate. J Med Entomol 1975, 11:667-687.

12. Taylor B: Changes in the feeding behaviour of a malaria vector, Anopheles farauti Lav., following the use of DDT as a residual spray in houses in the British Solomon Islands Protectorate. Trans R Entomol Soc London 1975, 127:227-292.

13. Taylor B, Maffi M: A review of the mosquito fauna of the Solomon Islands (Diptera: Culicidae). Pacific Insects 1978, 19:165-248.

14. Cooper RD, Waterson DGE, Frances SP, Beebe NW, Sweeney AW: Speciation and distribution of the members of the Anopheles punctulatus group (Diptera: Culicidae) in Papua New Guinea. J Med Entomol 2002, 39:16-27.

15. Hii JLK: Antimalaria program. WHO assignment report. (WP)MAL/SOL/ MAL/001-E. In Honiara, Solomon Islands: WHO Regional Office for the Western Pacific; 1988.

16. Detinova TS: Age grouping methods in Diptera of medical importance, with special reference to some vectors of malaria. World Health Organisation; 1962, Monograph 47.

17. Macdonald G: The analysis of the sporozoite rate. Trop Dis Bull 1952 49:569-586.

18. Killeen GF, Kihonda J, Lyimo E, Oketch FR, Kotas ME, Mathenge E, Schellenberg JA, Lengeler C, Smith TA, Drakeley CJ: Quantifying behavioural interactions between humans and mosquitoes: evaluating the protective efficacy of insecticidal nets against malaria transmission in rural Tanzania. BMC Infect Dis 2006, 6:161.

19. Beebe NW, Saul A: Discrimination of all members of the Anopheles punctulatus complex by polymerase chain reaction- restriction fragment length polymorphism analysis. Am J Trop Med Hyg 1995, 53:478-481.

20. Beebe NW, Ellis JT, Cooper RD, Saul A: DNA sequence analysis of the ribosomal DNA ITS2 region for the Anopheles punctulatus group of mosquitoes. Insect Mol Biol 1999, 8:381-390.

21. Bugoro H, Cooper RD, Butafa C, Iro'ofa C, Mackenzie DO, Chen CC, Russell TL: Bionomics of the malaria vector Anopheles farauti in Temotu Province, Solomon Islands: issues for malaria elimination. Malaria J 2011, 10:133.

22. MCAlpine JR, Keig G, Short K: Climate tables for Papua New Guinea. Division of Land Use Research Technical Paper No 37 CSIRO Australia; 1975.

23. Sloof R: Observations on the effect of residual DDT house spraying on behaviour and mortality in species of the Anopheles punctulatus group. Leyden University, Sythoff AW; 1964, PhD thesis.

24. Sweeney AW: A review of chemical control of malaria vectors in the south west Pacific. In Integrated Mosquito Control Methodologies Vol I. Edited by: Laird M, Miles JW. London: Academic Press; 1983:143-158.

25. Charlwood JD, Graves PM, Alpers MP: The ecology of the Anopheles punctulatus Group of mosquitoes from Papua New Guinea: A review of recent work. Papua New Guinea Med J 1986, 29:19-26.

26. Foley DH, Meek SR, Bryan JH: The Anopheles punctulatus group of mosquitoes in the Solomon Islands and Vanuatu surveyed by allozyme electrophoresis. Med Vet Entomol 1994, 8:340-350.

27. Cooper RD, Frances SP: Malaria vectors on Buka and Bougainville islands, Papua New Guinea. J Am Mosa Control Assoc 2002, 18:100-106.

28. Thevasagayam ES: Malaria control strategies in the Southwest Pacific countries - reappraisal. Proceedings of the Ninth South-West Pacific Malaria Meeting Sydney, Australia; 1983.

29. Daggy HR: The biology and seasonal cycle of Anopheles farauti on Espiritu Santo, New Hebrides. Ann Entomol Soc America 1945, XXXVIII:1-13.

30. Hii JLK, Birley MH, Kanai L, Foligeli A, Wagner J: Comparative effects of permethrin-impregnated bednets and DDT house spraying on survival rates and oviposition interval of Anopheles farauti No. 1 (Diptera: Culicidae) in Solomon Islands. Ann Trop Med Parasitol 1995, 89:521-529.

doi:10.1186/1475-2875-10-287

Cite this article as: Bugoro et al:: Changes in vector species composition and current vector biology and behaviour will favour malaria elimination in Santa Isabel Province, Solomon Islands. Malaria Journal 2011 10:287.

\section{Submit your next manuscript to BioMed Central and take full advantage of:}

- Convenient online submission

- Thorough peer review

- No space constraints or color figure charges

- Immediate publication on acceptance

- Inclusion in PubMed, CAS, Scopus and Google Scholar

- Research which is freely available for redistribution

Submit your manuscript at www.biomedcentral.com/submit
Biomed Central 